\title{
Leituras ao redor do silêncio
}

Readings around the silence

Deborah Walter de Moura Castro

UNIFAL - MG

\begin{abstract}
Resumo
Algumas obras do artista e poeta belga Marcel Broodthaers (1924-1976) são apresentadas nesse artigo como uma forma de trazer uma reflexão acerca da interseção entre a prática literária e artística, tendo como principal pilar leituras em torno do silêncio. Propondo uma nova relação entre poesia, artes e mídias, Broodthaers cria obras ressaltando os interesses gráficos do poeta, ao mesmo tempo em que oblitera as palavras. Essa desestabilização do poder das palavras trouxe para sua produção a ênfase na imagem porém em um espaço de escrita. Nas obras Un coup de dés e Pense-Bête, por exemplo, Broodthaers trabalha por cima de obras já existentes, distorcendo a ideia de originalidade, e principalmente explorando a vulnerabilidade da palavra e do sentido. Encobrindo palavras e engessando livros, Broodthaers chama atenção para a leitura do substrato, definido pelo poeta e crítico Craig Dworkin, em No Medium, como o que resta para ser lido. Assim, entre o dito e o não dito, palavra e imagem, Broodthaers suscita um novo olhar para o papel da literatura, das artes e das mídias.

Palavras-chave: Broodthaers; silêncio; substrato
\end{abstract}

\begin{abstract}
Some of the pieces by Belgium poet and artist Marcel Broodthaers (1924-1976) are presented in this article as a way to raise thoughts on the intersection between literary and artistic practices, having as its main pilar readings surrounding silence. Attempting a new relation between poetry, arts and media, Broodhtaers creates pieces highlighting the graphic interests of the poet as he obliterates words. This destabilization of the power of words brought to Broodthaers's works an emphasis on the image through in a writing space. In Un coup de dés and Pense-Bête, for example, Broodthaers works mainly over existing pieces, distorting the idea of originality, and most importantly, exploring the vulnerability of words and meaning. By covering words and plastering books, Broodthaers calls attention to the substract, definied by American poet and critic Craig Dworkin, in No Medium, as what is left to be read. This way, between the said and non-said, word and image, Broodthaers arouses a new look at the role of literature, arts and media.

Keywords: Broodthaers; silence; substract
\end{abstract}


Publicado na revista Cosmopolis um ano antes de sua morte, em 1897, Un coup de dés jamais n'abolirá le hasard (Um lance de dados jamais abolirá o acaso) ${ }^{1}$ foi o último poema do poeta francês Stéphane Mallarmé (1842-1898) conhecido muitas vezes por orientar a poesia moderna. Um lance de dados repensa o verso, a sintaxe e apresenta uma nova dimensão espacial com palavras distribuídas na página em diferentes fontes, tamanhos e recursos tipográficos, inventando o espaço moderno da poesia e novas possibilidades da letra. Mallarmé chamava seus versos de "subdivisões prismáticas da ideia", transformando-os em um tipo de imagem, ou dando tanta importância à forma quanto ao significado. Abstração e materialidade se contrastam em páginas duplas, ao tirar o rigor formal da poética do século XIX em uma escrita em verso livre e de certa forma antecipando, como o próprio "Mestre" do poema, tempos de incerteza.

Mallarmé estava libertando a leitura e em particular a poesia do espaço convencional da página de forma a abstrair tanto o conteúdo quanto a forma poética. No poema de Mallarmé as palavras descem gradualmente a página, dando ao poema um ritmo diferente. Em consonância com esse ritmo, a história é contada em seções, fragmentada, como evitando a linearidade da narrativa. $\mathrm{O}$ resultado dessa estratégia foi mais do que a autonomia do texto, porque incentivou uma espécie de apagamento do eixo semântico da linguagem como conhecido até então.

Em 1969, o artista belga Marcel Broodthaers reescreve Um lance de dados como um trabalho de apropriação. Broodthaers fez uma cópia da edição de 1914 do poema de Mallarmé transformando-o em um livro dele mesmo, publicado em 1969 como livro de artista. A capa do livro tem o nome de Broodthaers no topo (Marcel Broodhtaers), o título do poema logo abaixo (Un coup de dés jamais n'abolirá le hasard) impresso em caixa alta no centro da página, e a palavra image, em vez de poem - como na publicação de Mallarmé - abaixo do título e em tamanho menor, também em caixa alta. A palavra "imagem", a princípio, situa a obra não mais na categoria literária, mas dentro das artes visuais. Porém, tendo ainda como referente o poema e devido ao próprio título da exposição, Um lance de dados de Broodthaers estava de fato ofuscando os limites entre artes, letras e mídias. A primeira exibição desse trabalho foi na galeria Wide White Space, na Antuérpia, sob o título 'Exposition Littéraire autour de Mallarmé', o que confirmava a apropriação de Broodthaers, seu interesse em outras mídias, significados obscuros e colocando em evidência a problemática da classificação.

Nesse pastiche editorial, Broodhtaers deu ao poema uma nova visibilidade colocando

1 MALLARMÉ, Stéphane. Um lance de dados jamais abolirá o acaso, 2006, p. 153-73. 
também em xeque noções de originalidade. Com o refinamento do minimalismo, essa obra abafa, discretamente, o 'original'. Em O gênio não original, Marjorie Perloff (2013) explica o termo reescritura, que Antoine Compagnon chama de linguagem de citação, como uma prática que é hoje lugar-comum no discurso digital, celulares e Facebook, frequentemente desvinculada da originalidade pois muitas vezes a fonte é indeterminada. Perloff explica que "a apropriação, a citação, a cópia, a reprodução - essas coisas há décadas são centrais às artes visuais"2. Compagnon diz que "a reescrita é uma realização" e também que "o trabalho da citação [...] é uma produção de texto" ${ }^{3}$. Em Um lance de dados, de Broodhtaers, essa reescrita é uma prática que não se resume à intertextualidade, mas à criação sob/re a criação. A obra de Broodthaers é uma produção que se inspira e homenagea o autor do poema primeiro. É feita, como a próprio título da exposição sugere, "ao redor de Mallarmé".

Broodthaers dizia que Mallarmé foi o profeta que anunciou o século XX, referindo-se à maneira como ele usava o espaço para dispor elementos léxicos na página. Nas mãos de Broodthaers o poema de Mallarmé foi reduzido à sua forma gráfica. Broodthaers silenciou o poema ao encobrir suas palavras com tarjas negras, respeitando o tamanho do tipo no poema original assim como o comprimento das linhas. As tarjas variam em espessura de acordo com o tamanho dos versos, mas sempre encobrindo completamente as palavras, sem deixar nenhum rastro do que poderia estar escrito sob o bloco de tinta. Com os blocos retangulares, a dimensão espacial das palavras é apreendida em sua totalidade, sem a ordem impositiva da escrita. Devido à estratégia de obliteração, os olhos se fixam no todo, ou em qualquer ponto, como se mirassem o céu para se dar conta das estrelas, perpassando constelações. Não há na apreensão da obra um caminhar da esquerda para a direita, como espera-se de uma leitura convencional, tornando o exercício de leitura impossível, e a palavra irrecuperável.

A obliteração das palavras sugere a definitiva opacidade da linguagem, que perde sua forma, seus contornos e seu significado. $\mathrm{O}$ ato de cobrir as palavras reforça a presença física e material da linguagem já que, para que fossem encobertas, demandaram um material que se sobrepusesse à sua própria materialidade. Isto é, para que a palavra surja em papel, é necessário seu desenho gráfico, em tinta, por exemplo. E para que seja encoberta, é preciso uma nova cobertura, uma nova e mais abrangente camada de tinta.

O signo agora é a interdição, o borrão. A retórica de seu texto é a de uma presença implosiva, em que Broodthaers atesta a insuficiência das representações visuais e textuais ${ }^{4}$. $\mathrm{O}$ trabalho de Broodthaers se recusa a passar uma mensagem clara ao espectador. A mensagem

2 PERLOFF, Marjorie. O gênio não original, 2013, p. 56.

3 COMPAGNON, Antoine. O trabalbo da citação. 1996, p. 46.

4 SCHWARZ, Dieter. "Look! Books in plaster!", 1988. p. 57-66. 
não está nem no texto, nem na imagem. Texto e imagem demonstram uma interação instável. $\mathrm{O}$ artista parece estar examinando a ligação entre visível e legível e sua relação com o trabalho de arte, o lugar, a exposição, a livraria. Segundo Buchloh, "o apagamento semântico e visual - o comprometimento da leitura das marcas linguísticas - surge para dar autonomia plástica e uma presença como um objeto aos elementos tipográficos, mas por meio da linguagem, em nome

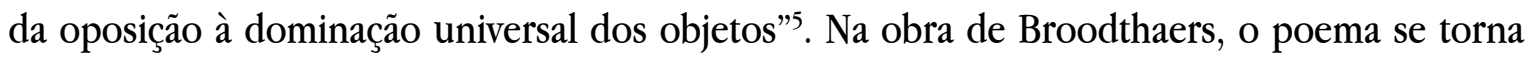
um objeto.

O leitor/espectador se depara com a função de desvendar suas estratégias de apagamento, implicando em resultados indeterminados e incertos. O leitor/espectador, antes à escuta, se vê intrigado diante de rasuras e apagamentos e entregue a ausência de palavras e de sentido. Nesse trabalho fica claro, e cito Broodthaers, "a esperança de que o espectador corra o risco

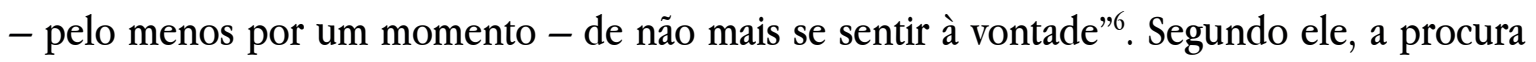
de significados escondidos sob a superfície tende a encobrir o óbvio. Mas o que seria o óbvio? A própria evidência gráfica? Ou a materialidade das palavras? O que afinal balbucia a obra de Broodhtaers? Afinal, qual o sentido da obra? Além de destacar a distribuição do poema na página, há alguma outra característica do poema de Mallarmé que deve ser resgatada? É necessário que voltemos às palavras de Mallarmé para que consigamos dar sentido a obra de Broodthaers?

A partir dessas questões, concluímos ao menos que ao redor do apagamento e do silêncio está o caminho para nossa leitura. O apagamento não é apenas do texto do autor, mas a evidência do que antes não era o mais evidente. $\mathrm{O}$ artista está desconstruindo e reconstruindo textos e gêneros, revendo o poder da linguagem verbal, a tarefa do escritor, a função da escritura, a leitura e a criação de sentidos. O primeiro texto é agora mais silencioso com o papel distinto de dizer o que não foi dito, o que não pode ser dito, ou a única coisa que deveria ser dita.

Quando Broodthaers utiliza uma tarja preta sobre as palavras, sua obra passa a margear o silêncio. Margear porque o silêncio nunca é abordado em sua totalidade. Revezando com a linguagem verbal a árdua tarefa de significar, o silêncio sempre aponta para um murmúrio, uma palavra escondida. Sempre há palavras por trás do silêncio, assim como cada palavra carrega em si um aspecto silencioso. Não é possível pensar em um silêncio absoluto, que não signifique ou apresente ruídos. "Ser silencioso não é o silêncio absoluto, mas um volume baixo de som.

5 Minha tradução de: "Semantic deletion and visual erasure - the undermining of the legibility of linguistic marks - emerged to give plastic autonomy and an object like presence to the elements of typography, but did so through language, in the name of an opposition to the universal domination of objects" (BUCHLOH, Benjamin. "Open letters, industrial poems", 1988. p. 76).

6 Minha tradução de: "the hope that the viewer runs the risk - for a moment at least - of no longer feeling at ease" (BROODTHAERS, Marcel. "Ten thousand francs reward", p. 43). 
Enquanto estamos vivos, jamais há o silêncio pleno"7. Esse silêncio absoluto seria aterrorizante, como o silêncio da anti-história, do caos que procedeu a criação mitológica. O silêncio absoluto está relacionado ao fim da vida, à morte, ao inaudível, ou à desconexão com o tempo, ao fim dos tempos.

A característica silenciosa na obra de Broodhtaers não é portanto uma ausência, ou a falta da linguagem verbal, mas presença. Independentemente de sua forma, o silêncio é significante. Independentemente se entendido como ausência ou presença, o silêncio é definido pelo sentido que a ele atribuímos. Francis Wolff explica que:

\begin{abstract}
de maneira mais geral, sempre é possível escutar o silêncio não apenas como uma ausência, como a negação de algo que lhe falta, mas como certa presença, certa maneira de remeter a algo diferente; e essa presença se encontra nele, talvez, como sua negação - sons quase imperceptíveis, por exemplo -, mas se encontra mais seguramente fora dele - é o sentido que lhe atribuímos. ${ }^{8}$
\end{abstract}

Se nos ativermos à compreensão do silêncio como ausência, partimos do princípio de que, para que o silêncio esteja presente, algo deve estar ausente, como se o silêncio só acontecesse quando alguma coisa é afastada. O silêncio como ausência implica a inexistência de alguma coisa, agora substituída pela presença do silêncio. Desta forma acabamos situando-o não como ausência, mas entre presença e ausência. A conclusão é que, independentemente das formas do silêncio, sua natureza é ambivalente, e falar do silêncio permite problematizar sua natureza.

O silêncio de uma página em branco, por exemplo, que já foi oculto pela representação gráfica da linguagem escrita, retorna tentando encobri-la com nova significação. Dar sentido a esse silêncio não é apenas uma tarefa discursiva, mas trabalha o não dito como posterior ao dito. É um silêncio gráfico, visível, estético, evidenciado pelos rastros materiais de seus passos, como uma palavra recortada na página ou, nesse caso, uma tarja preta sobre uma frase. É esse silêncio significante, essa espécie de rasura, ou perda, que permite uma nova leitura. Essa perda, paradoxalmente, acaba por salvar o sentido do texto/obra em outra instância, menos óbvia, mais opaca. É nessa opacidade, e não na esperada transparência, que a escrita desaparece?.

No primeiro capítulo do livro No medium, de Craig Dworkin, chamado "The logic of substrate", o autor explica o substrato como aquele que surge como um objeto com propriedades materiais, detentor de histórias e potencial significante. O substrato aparece como um dispositivo

7 DUARTE, Pedro. "O silêncio que resta", 2014, p. 132

8 WOLFF, Francis. "O silêncio é ausência de quê?", 2014. p. 46

9 DWORKIN, Craig Douglas. Reading the illegible, 2003. 
formal. É aquilo que resta mas que ainda permite leitura - uma leitura que está entre alguma coisa ou coisa alguma ${ }^{10}$. Mesmo podendo estar à espera ou à procura da palavra ausente, o leitor deve perceber outros signos presentes e capazes de se comunicar. Na ausência da materialidade da palavra, há outros materiais capazes de proporcionar uma leitura. Segundo Pierre-Marc de Biasi, "é por meio da rasura que a produção do texto tem andamento"11. A rasura passa a ser parte dessa escrita do silêncio, uma parte da redação e da constituição de um novo texto. Na rasura tira-se palavras, às vezes para deixar outras, outras vezes para eliminá-las por completo. As tarjas pretas não escondem, mas revelam. O verdadeiro interesse está na capacidade cognitiva do leitor/espectador.

O poema "Lautgedicht" (1924), do americano Man Ray (1890-1976) ${ }^{12}$, é um exemplo da materialidade poética das tarjas negras. O título do trabalho a princípio traduz o oposto do que demonstra. "Lautgedicht" ("Poema sonoro") é uma junção de duas palavras em alemão: laut, que significa alto, sonoro, em voz alta; e gedicht, que significa poesia, poema. Ironicamente, o título prepara o leitor/espectador para um poema sonoro, um poema vocalizado. Mas como vocalizar um poema que não tem indicações decifráveis de som?

As tarjas reforçam a ideia do texto impresso, escrito. Se em vez das tarjas pretas tivéssemos palavras, a impressão ainda colocaria o texto escrito como subsidiário do texto falado, uma vez que esse é um poema sonoro, ou assim esperava-se. O texto escrito, nesse caso, poderia ser um mero registro daperformance vocal, ou contar com a participação do leitor, que deveria ler o poema em voz alta. Com as tarjas pretas no lugar da linguagem verbal, tem-se não o registro da oralidade, mas do silêncio, da voz abafada.

Novamente, o efeito dessa tarja preta é a eliminação dos traços semânticos que a linguagem verbal oferece, ao mesmo tempo em que sustenta a permanência de sua materialidade. $O$ poema implica sua característica puramente material, não necessariamente a materialidade da linguagem verbal. Diferentemente de Um lance de dados, o poema de Ray não tem palavras, e de fato nunca teve.

Além da indicação do próprio título, o poema é visível e reconhecido apenas pela disposição das linhas, do título centralizado, e das quatro estrofes. São esses os recursos que permitem ao leitor/espectador a identificação de um poema. O ritmo, os artigos ou preposições, provavelmente implícitos ou escondidos nos traços menores, reforçam nosso reconhecimento e até desejo de reescrever o poema. Mas a linguagem verbal não é o que se espera dessa leitura.

10 DWORKIN, Craig. No medium, 2015.

11 apud GUIMARÃES, Julio Castañon. "Alguns lances de escrita", 2004, p. 83.

12 RAY, Man. Lautgedicht, 1989, p. 18. 
O significado verbal não é aqui definitivo para que haja um poema, ou para que "Lautgedicht" seja lido como tal.

Assim como em Um lance de dados, não é a ausência do texto verbal que atribui a essa obra algum sentido, mas o que está presente. Sabemos através das tarjas o quanto já sabemos: há um modelo visual para que se identifique um poema, e a ausência das palavras não atrapalha em nada essa identificação. Como um poema concreto, a forma é tão importante que se torna conteúdo. Mais uma vez, enquanto a estrutura física e material do poema impede a comunicação como esperada, um outro sentido está sendo transmitido por essa mesma materialidade ${ }^{13}$. É essa a leitura do substrato, do que temos a nossa disposição. Para entender melhor o silêncio de Broodhtaers, é importante entender também um pouco de sua trajetória.

$* * * * *$

Birgit Pelzer define a produção de Broodthaers em três etapas: 1949, 1958 e 1964. A primeira etapa é definida por seus primeiros trabalhos como escritor, com publicações de poemas em revistas com tendências surrealistas e como jornalista na revista comunista Le Salut Public. A partir de 1958, apresentou atividades esparsas e fragmentadas, começando por um filme experimental sobre Kurt Schwitters, exibido em um festival no mesmo ano, em Knokke. Finalmente, em 1964, início da última etapa, segundo Pelzer, e também está nesta etapa Un coup de dés, Broodthaers iniciou uma produção regular inaugurada pela obra Pense-Bête ${ }^{14}$.

Em 1964, Broodhtaers produziu sua primeira escultura, Pense-Bête, exibida no mesmo ano na galeria Saint-Laurent, em Bruxelas, e vencedora do Prix de la Jeune Sculpture no Palais de Beaux-Arts, também naquela cidade.

Pense-Bête, em francês, é um aide-mémoire ou lembrete, uma anotação, um bilhete. Pense-Bête também dá a ideia de um "pensamento bobo", ou, como um jogo de palavras feito por Broodthaers, pode ser traduzido também como "pense-besta". Todas as possibilidades que carregam o termo Pense-Bête inviabilizaram sua tradução para o inglês ou português, pelo menos dentro da abordagem escolhida, uma vez que reduziriam o termo a uma única possibilidade, esvaziando a ampla dimensão pensada por Broodthaers.

Para a confecção dessa obra, Broodthaers reuniu 50 cópias de seu livro de poesia, intitulado Pense-Bête, lançado em 1963 (um ano antes da exibição), e deu a elas um caráter escultural. Essas 50 cópias do livro que publicara como poeta estavam ainda parcialmente embrulhadas no papel original e foram unidas por uma massa de gesso em sua base fazendo com que os livros

13 DWORKIN, Craig Douglas. Reading the illegible, 2003.

14 PELZER, Birgit. "On the proper use of masks: the writings of Marcel Broodthaers, poet", 2012. 
ficassem lado a lado, em pé, formando um bloco ${ }^{15}$. Esse gesto, a princípio, impede a leitura dos livros. Porém, removê-los dessa base parece possível, já que a escultura tem um aspecto improvisado ou até temporário.

As cópias recebiam agora o status de uma escultura, de um objet trouvé, um readymade. Nesse livro objeto, o livro ainda era reconhecido e as páginas, na parte superior, ficavam ligeiramente soltas, permitindo uma espiada no seu interior. Quando a obra foi exibida pela primeira vez, ao contrário do que pensou Broodthaers, os espectadores nem tentaram ler ou saber o conteúdo de seus livros, mas aceitaram, talvez com alguma hesitação, a condição de obra de arte, de livro objeto. Os 50 livros perderam sua função primeira. Os poemas de Broodhtaers foram trancados, privados de intervalos, palavras ou significados. As únicas palavras que ainda soavam vinham do título do livro de poemas, estampado na capa, homônimo do agora nome da obra: Pense-Bête.

A primeira impressão do gesto de Broodthaers ao silenciar seus poemas é que o artista estivesse negando sua carreira como poeta. Impedir a leitura de seus livros, de seus poemas, é como uma afronta ao fazer literário, quase como um ato de censura do autor em relação a sua produção, como um ato proibitivo ou uma força opressiva. As 50 últimas cópias de seu livro não podiam mais circular, ser vendidas, manuseadas ou lidas. Os livros ganharam uma segunda vida e, se algo permanece de seus poemas, é a memória do que uma vez foram, o que não parecia importar para o público.

Na condição de obra de arte, o que está no interior não interessa. Os poemas perderam seu valor. O gesto de Broodthaers é simbólico e experimental. Além da possibilidade dessa obra simbolizar o fim da carreira de Broodthaers como poeta, ela permite, por essa zona de silêncio que ele mesmo criou, uma ode à sua transição de poeta a de artista.

Esse ato se tornaria comum nas práticas de Broodthaers que, ao mesmo tempo em que deleta, conserva. Ele estava criando um espaço que testava os limites entre a poesia e as artes visuais, entre textos, imagens e objetos, entre autor e leitor. Nessa intercessão, Broodthaers desenvolve sua carreira como "criador". Segundo o artista, como ele não conseguiria desenvolver uma coleção de suas obras por não ter os meios financeiros, ele não teve alternativa a não ser lidar com sua criação de outra maneira: com má fé. Ele concluiu que seria um "criador", em vez de um artista, implicando que agiria com uma maravilhosa indiferença. Esse era o gesto político de Broodthaers.

Em Reading the illegible, Craig Dworkin diz que política, em um sentido mais amplo, incluiria todas as relações de poder e a ética da distribuição dessas relações. Dworkin explica que a política da literatura apresenta modelos nos quais os leitores podem extrapolar as modalidades

15 SCHWARZ, Dieter. “Look! Books in plaster!", 1988. 
de pensamento ou comportamento, traduzindo-os para outros contextos ou sistemas. Poemas, por exemplo, podem afetar a compreensão que um leitor tem da linguagem, alterando todas as relações extraliterárias que envolvem também a linguagem, em uma expansão para o âmbito social. O gesto político de Broodthaers colocava suas formulações entre afirmações ou negações, ou entre o que ele diz ou deixa de dizer, ou apenas em uma expansão do sentido de leitura.

O convite para sua exposição na galeria Saint-Laurent começava com uma frase que acabou ficando conhecida no mundo da arte e se tornou representativa da prática que Broodthaers passaria a adotar: "Eu também me perguntei se um dia não poderia vender algo e ter sucesso nessa vida". Todo o conteúdo do convite era, na verdade, de uma natureza surpreendente, na qual Broodthaers expunha uma sinceridade quase ofensiva. O convite trazia o seguinte texto, impresso sobre propagandas em folhas de revista:

\author{
Eu também me perguntei se um dia não poderia vender algo e \\ ter sucesso nessa vida. Já faz algum tempo que não sou bom \\ em nada. Tenho quarenta anos... \\ Por fim, a ideia de inventar algo insincero cruzou meu \\ pensamento e me pus a trabalhar. Ao fim de três meses \\ mostrei o que havia produzido a Philippe Edouard Toussaint, \\ o proprietário da galeria \\ Saint Laurent. Sim, isso é arte, ele disse, e eu estaria disposto \\ a exibir tudo. Concordo, respondi. \\ Se algo for vendido ele fica com 30\%. Parecem ser as condições \\ normais. \\ Certas galerias ficam com $75 \%$. E o que são? De fato são \\ objetos. Marcel Broodthaers \\ Galerie St. Laurent rua Dequesnoy De 10 a 25 de abril \\ Inauguração sexta feira 10 de 18 às $20 \mathrm{~h}^{16}$
}

Nesse convite, Broodthaers não apenas admite seu fracasso até os 40 anos de idade, provavelmente financeiro, como deixa explícito seu desejo de vender algo, e não necessariamente de produzir uma obra de arte genuína, que viria de uma inspiração ou de uma necessidade

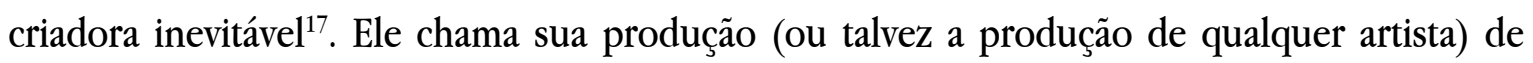
insincera, e deixa clara a natureza mercadológica da arte. Com esse convite Broodthaers tira da

16 BROODTHAERS, Marcel. "Convite para exposição", 2014, p. 284.

17 KERN, Keila. Marcel Broodthaers Museu de Arte Moderna Departamento das águias Agora em Português, 2014. 
arte o encantamento da execução e expõe as condições das instituições de arte na negociação de uma exposição.

Aqui se consolida o paradoxo do mentiroso formulado por Broodthaers, no qual ele está mentindo, mas também falando a verdade, como se ele fosse algo como um mentiroso honesto. Ao mesmo tempo em que ele se assume mentiroso por não apresentar a posição de artista esperada, mas sim de alguém que quer se aproveitar do mercado artístico para ganhar dinheiro, ele torna pública sua posição. Broodthaers está expondo a crise econômica de ser poeta e transferindo sua carreira ao mercado falso que sustenta o mundo da arte, de maneira que ataca os museus e as instituições que representam esse mercado. Isso faz com que as obras de Broodthaers, seus objetos, se situem em uma produção que se encontra no limiar entre o fazer e a crítica - uma prática comum aos artistas conceituais.

A concepção do Departamento das Águias em seu Museu de Arte Moderna, criado por ele em sua própria casa, foi idealizada a partir da águia, que, segundo Rosalind Krauss, funcionava como um emblema da arte conceitual para Broodthaers. Nesse museu fictício, instituído entre 1968 e 1972, Broodthaers questionava noções de coleção e representação, original e cópia, artista e sociedade. Krauss explica que "o triunfo da águia anuncia não o fim da arte mas o término das artes individuais como uma mídia/específica" ${ }^{18}$. Levando a águia para todas as instâncias de sua produção artística, Broodthaers mostra que tudo, no final das contas, está sujeito às regras do mercado econômico. Ao mesmo tempo em que Broodthaers submetia sua produção às regras mercadológicas do mundo da arte, ele distorcia esses mecanismos ao mostrar as estruturas que sustentavam esse mesmo mercado. Ele estava espelhando em suas obras o funcionamento do mercado. Broodthaers estava se dirigindo às estruturas ocultas no mundo da arte, inaugurando, com Hans Haacke, Daniel Buren e Michael Asher, a "crítica institucional".

\section{$* * * * *$}

Durante a $27^{\mathrm{a}}$ Bienal de São Paulo, uma série de conferências foram realizadas sob o título "Marcel 30", em homenagem a Broodthaers. Na conferência "Correspondências para além do silêncio", Dorothea Zwirner explica o que significou o termo "crítica institucional" e como ele surgiu. Para Zwirner, é no museu que a arte moderna floresce. A arte moderna nasce nos museus com pinturas autônomas, como os quadros de Monet. O museu passa a definir o que é ou não é arte. Isto é, a arte autônoma floresce sob a proteção do museu. A primeira centelha da

18 Minha tradução de: "the triumph of the eagle announces not the end of Art but the termination of the individual arts as medium/specific; and it does so by enacting the form that this loss of specificity will now take". (KRAUSS, Rodalilnd. "A voyage on the north sea", 1999, p. 12) 
crítica institucional aconteceu em 1917, com o urinol de Duchamp, objeto comum e sem autor definido, que só funcionaria como arte no contexto de exposição ${ }^{19}$.

Zwirner fala também das correspondências, que são como o cerne da arte, pois corresponder é ser equivalente a, ou é como uma troca de cartas, que pressupõe a existência de uma contraparte, o que implica interação, negociação. Para Zwirner, arte sempre foi sobre correspondência; correspondência entre imagem e sua reprodução, a palavra e o sentido, ficção e realidade, arte e vida. Ela enfatiza que, desde o Romantismo, a arte procura uma resposta definitiva para o paradoxo entre a presença e a ausência. Mas, enquanto os românticos procuravam uma unidade ou completude entre as partes, a contemporaneidade enfatiza o múltiplo. De qualquer forma, não há uma relação conclusiva entre a abstração e o objeto, o significado e o significante.

Entre essa abstração e o objeto está o silêncio de Broodthaers, situado entre as correspondências no universo artístico, entre sua imagem e o poema de Mallarmé, por exemplo, num espaço que ele cria desvinculado de categorias estanques ou leituras preestabelecidas.

Gloria Moure, em Marcel Broodthaers: collected writings, introduz essa compilação dizendo que se existe um termo capaz de caracterizar de forma genérica o trabalho de Broodthaers, este termo é o espaço da escritura, "l'espace de l'écriture"20. Em meio a poemas, textos, obras de arte e filmes, é principalmente nesse espaço que toda a diversidade midiática de Broodthaers emerge e depende.

Pode-se pensar que esse espaço a qual Moure se refere seja a estratégia utilizada por ele em grande parte de sua criação que ressalta o lugar entre o sentido e a falta dele. Para o artista, a ficção é uma forma de apresentar a realidade, principalmente o que está velado na realidade. Quando criou o museu fictício, formou uma rede artística de produções que variavam em forma (fotografia, pintura, instalação), em disciplinas (poesia, história, sociologia), em movimentos (surrealismo, pop arte, arte conceitual) e textos (revisões, críticas, poemas). Na abertura das conferências da $27^{\mathrm{a}}$ Bienal, Marie-Puck Broodthaers, filha de Marcel Broodthaers, agradeceu à Bienal por acolher as obras de seu pai, e comentou a incompreensão de sua arte por parte do público e da crítica, complementando com uma frase do próprio Broodthaers: "deixemos que os historiadores da arte se enganem" ${ }^{21}$. Portanto tentar fechar uma leitura em torno do silêncio de Broodhtaers seria cair na armadilha que ele criou.

A leitura em torno do silêncio nos trabalhos de Broodhtaers se funde num amálgama de estratégias e mídias que questionam, continuamente, o papel do poeta, do artista, da

19 ZWIRNER, Dorothea. "Marcel Broodthaers: correspondências além do silêncio", 2008. p. 75-88.

20 MOURE, Gloria. "L'espace de l'écriture", 2012, p. 13.

21 apud SPRICIGO, Vinícius. Abertura do Seminário "Marcel 30", 2006. 
obra de arte, e da instituição. Toby Kamps explica que, em 1972, na performance Speakers Corner, Broodhtaers foi ao famoso lugar de debates e discursos em Hyde Park, onde oradores dissertavam livremente sobre tópicos que variavam entre política ou religião. Ele foi à frente e permaneceu em silêncio, escrevendo apenas uma série de advertências em um quadro, como "Atenção", "Silêncio por favor", "Visite a Tate Gallery" e "Vocês são artistas". Indiferente a risos e provocações vindos do público, Broodthaers se manteve mudo. O silêncio foi usado para subverter o próprio espaço de subversão (KAMPS, 2012). Por isso o silêncio nessas e em várias outras obras de Broodthaers é fundamental para a criação dessa poética de cunho sociocultural, sem esquecer que é por vezes bem-humorado. Os trabalhos de Broodthaers são como um poema ilegível, de acesso obscuro, em que palavras e silêncios se abrem a interpretações e comentários em uma composição que faz o leitor tatear para além do que parece sem sentido, nonsense, em busca de uma nova estética, ou de seu próprio espaço de escritura.

Tanto em Um lance de dados quanto em Pense-Bête, Broodthaers exercita a ilegibilidade do "original", trabalhando em cima de outros textos, violando e apropriando do poema de Mallarmé e de seus próprios de forma a apagá-los e silenciá-los para escrever através. Cria assim um novo texto, mais reduzido, menos claro, menos legível, mais ideológico e político. Qualquer que seja o significado do silêncio nas obras de Broodthaers, seja ele sinônimo de calma, inquietude, abstenção ou murmúrio, ele está mais próximo de um desvio do vigente, um alerta ao obscuro.

Em Linguagem e silêncio, George Steiner diz que o Apóstolo nos contou que o começo era o verbo e que aceitamos essa realidade sem discussão. "É a raiz e o córtex de nossa experiência e não podemos transportar facilmente nossa imaginação para fora dele. Vivemos no interior do ato do discurso"22. Mas ele admite que "existem atividades do espírito enraizadas no silêncio", conjurando na nossa consciência uma lacuna existente "entre a nova compreensão de realidade psicológica e as antigas modalidades de manifestação retórica e poética"³. Steiner indicava a crise dos recursos poéticos, que começou no final do século XIX, através de uma libertação das limitações da sintaxe e da definição, como em Rimbaud e Mallarmé. Não havia a possibilidade de um retorno ao que havia antes da linguagem verbal, mas depositar menos confiança nas palavras ou propor novas experiências já era uma forma de subversão.

Por meio do silêncio, o escritor tenta um retorno a uma linguagem menos contaminada. Silêncio e linguagem firmam uma relação que proporciona uma escrita menos submersa nas torrentes das palavras. Mas a verdade é que o silêncio é apenas uma tentação. Ao acentuar obras em torno do silêncio, Broodthaers parece se dar conta das amarras da linguagem verbal,

22 STEINER, George. Linguagem e Silêncio, 1988, p. 30.

23 Ibidem, p. 30. 
da nossa própria subordinação a ela e, principalmente, da impossibilidade do silêncio pleno. Talvez seja o silêncio então a maior ambição dos poetas/artistas, e a palavra sua maior tentação.

Assim como a epígrafe desse artigo, as obras de Broodthaers não requerem um mergulho nos mares das palavras, o que paradoxalmente acabei por fazer, mas uma compreensão das constelações como as de Mallarmé, por exemplo, sem nomeá-las ou interpretá-las. Agora branco e negro, página e letra, silêncio e palavra revezam em importância, como céu e estrela, ainda que embaçados pelo ímpeto da significação. Mais do que simbólico, o poema de Broodthaers é experimental, e enquanto Mallarmé inaugura, com Um lance de dados, os caminhos da poesia moderna, Broodthaers reforça sua relevância visual, agora sem versos ou devaneios, e carregando consigo todas as referências de seus trabalhos, de percepções midiáticas, artística, políticas, sociais e institucionais, como explorado nesse artigo. As obras ao redor do silêncio não se referem simplesmente à exaltação da opacidade material das palavras, mas sua função pouco óbvia ao expressar significados. Assim como o silêncio, a palavra não dá acesso a uma via direta para se chegar à ideia. O caminho da significação é naturalmente tortuoso e cheio de encruzilhadas. As obras de Broodhtaers apontam para uma rede de significados que se expandem para além da leitura de palavras e silêncios, tocando em pontos de percepção das formas de comunicação, das artes, das letras e das mídias e tirando do leitor a posição confortável de ler o que pode ser encontrado em dicionários. Mais do que um silêncio experimental, as leituras em torno do silêncio refletem todo o universo para onde pode apontar a letra, sem muitos encantos, mas em seu espaço específico e com toda a estrutura que o mantém. 


\section{Referências}

BROODTHAERS, Marcel. Convite para exposição. In: KERN, Keila. Marcel Broodthaers Museu de Arte Moderna, Departamento das águias, Agora em Português. Tese (doutorado). Escola de comunicação e artes - USP, São Paulo, 2014. p. 284

BROODTHAERS, Marcel. "Ten thousand francs reward"(1974). In: BUCHLOCH, Benjamin H. D. (Ed.). Marcel Broodthaers: Writings, interviews, photographs. Boston: MIT, 1988. p. 39-48.

BUCHLOH, Benjamin. "Open letters, industrial poems". In: BUCHLOCH, Benjamin H. D. (Ed.). Marcel Broodthaers: Writings, interviews, photographs. Boston: MIT, 1988. p. 67-100.

COMPAGNON, Antoine. O trabalho da citação. Trad. Cleonice P. B. Mourão. Belo Horizonte: UFMG, 1996.

DUARTE, Pedro. "O silêncio que resta". In: NOVAES, Adauto (Org.) Mutações: O silêncio e a prosa do mundo. São Paulo: Edições Sesc São Paulo, 2014. p.131-150.

DWORKIN, Craig Douglas. No medium. Cambridge: MIT: 2015.

DWORKIN, Craig Douglas. Reading the illegible: avant-garde and modernism studies. U. California: Berkeley, 2003.

GUIMARÃES, Julio Castañon. "Alguns lances de escrita". In: SÜSSEKIND, Flora e GUIMARÃES, J. C. (org.). Sobre Augusto de Campos. Rio de Janiero: 7 Letras: Fundação Casa Rui Barbosa, 2004.

KAMPS, Toby; SAID, Steven (Org.). Silence. Houston: The Menil Collection, 2012.

KAMPS, Toby. “(...)”. In: KAMPS, Toby; SAID, Steven (Org.) Silence. The Menil Collection. New Haven, Yale University Press: 2012. p.63-82.

KERN, Keila. Marcel Broodthaers Museu de Arte Moderna, Departamento das águias, Agora em Português. Tese (doutorado). Escola de comunicação e artes - USP, São Paulo, 2014.

KRAUSS, Rosalind. "A voyage on the north sea": art in the age of the post-medium condition. Nova York: Thames \& Hudson, 1999.

MALLARMÉ, Stéphane. Um lance de dados jamais abolirá o acaso. Trad. Haroldo de Campos. In: CAMPOS, Augusto de,; CAMPOS, Haroldo de,; PIGNATARI, Décio. Mallarmé. 3. ed. São Paulo: Perspectiva, 2006. p. 153 - 173.

MOURE, Gloria. "L'espace de l'écriture". In: MOURE, Gloria (Ed.). Marcel Broodhtaers: Collected Writings. Barcelona: Edciones Polígrafa, 2012. p. 13-20.

PELZER, Birgit. "On the proper use of masks: the writings of Marcel Broodthaers, poet". In: 
MOURE, Gloria (Ed.). Marcel Broodbtaers: Collected Writings. Barcelona: Edciones Polígrafa, 2012. p. $22-35$

PERLOFF, Marjorie. O gênio não original: poesia por outros meios no novo século. Tradução de Adriano Scandolara. Belo Horizonte: UFMG, 2013.

RAY, Man. Lautgedicht In: BRADFORD, Richard. "The visual poem in the eighteenth century". Visible language journal. Vol.23 Issue 1. p. 9 - 27. jan. 1989.

Disponível em: < https://s3-us-west-2.amazonaws.com/visiblelanguage/pdf/23.1/the-visualpoem-in-the-eighteenth-century.pdf > Acesso em: 21/07/2020.

SCHWARZ, Dieter. "Look! Books in plaster!" In: BUCHLOCH, Benjamin H. D. (Ed.). Marcel Broodthaers: Writings, interviews, photographs. Boston: MIT, 1988. p. 57-66.

SPRICIGO, Vinícius. Abertura do Seminário "Marcel 30", 27a Bienal de São Paulo. Forum Permanente. São Paulo: 2006. Disponível em: < http://www.forumpermanente.org/administ/ bienal-marcel/marcel30doc/marcel30-abertura $>$ Acesso em: 01/08/2015.

STEINER, George. Linguagem e Silêncio: ensaios sobre a crise da palavra. Trad. Gilda Stuart e Felipe Rajabally. São Paulo: Companhia das letras, 1988.

WOLFF, Francis. "O silêncio é ausência de quê?" In: NOVAES, Adauto (Org.) Mutações: O silêncio e a prosa do mundo. São Paulo: Edições Sesc São Paulo, 2014. p.31-51.

ZWIRNER, Dorothea. "Marcel Broodthaers: correspondências além do silêncio". In: LAGNADO, Lisette (curadora). 27 $7^{a}$. Bienal de São Paulo: conferências. Rio de Janeiro: Cobogó, 2008. p. 75-88. 